\title{
Inmigración, propiedad común de la tierra e igualitarismo de la suerte global. Un análisis de la teoría de Mathias Risse*
}

\author{
Daniel Loewe \\ Universidad Alfonso Ibáñez
}

\begin{abstract}
Resumen: El artículo presenta y examina la teoría de la propiedad común de la tierra articulada y defendida por Mathias Risse, enfocándose en el caso de la inmigración, y arguye que la teoría tiene dificultades tanto inmanentes como con respecto a sus consecuencias, de modo que no puede hacerse cargo de los flujos migratorios que se retrotraen a la desigualdad económica en términos de justicia. Finalmente, en contraposición, se presenta una defensa de las fronteras abiertas en base a una concepción igualitarista de la suerte global.
\end{abstract}

Palabras clave: Risse; propiedad común de la tierra; inmigración; necesidades básicas; demanda de conducta razonable

\begin{abstract}
Immigration, Common Ownership of the Earth and Global Luck Egalitarianism. An Analysis of Mathias Risse's Theory". This paper presents and examines the theory of common ownership of the earth articulated and defended by Mathias Risse, focusing on the case of immigration. We argue that this theory has serious difficulties, both immanent and with regard to its consequences, and accordantly it cannot take charge of the migratory flows that go back to the economic inequality in terms of justice. Finally, as an alternative to this proposal, a defense of open borders based on a global luck egalitarian conception is presented. Keywords: Risse; common ownership of the earth; immigration; basic needs; demand of reasonable conduct
\end{abstract}

\footnotetext{
* Este trabajo se inscribe en el proyecto -Fondecyt 1160982.
} 
La idea de un mundo común ha ocupado un espacio importante en los desarrollos de la filosofia política, usualmente como teorías de posesión común de la tierra. Podemos encontrar la idea en muchos autores. Por ejemplo, en la tradición del derecho natural se destacan los desarrollos de Vitoria, Grocio y Locke. Un desarrollo de esta idea, respaldando una obligación cosmopolita de hospitalidad universal, la encontramos en La paz perpetua de Kant ${ }^{1}$. En la actualidad, por referencia a la teoría de Grocio, Mathias Risse ha defendido vigorosamente en On Global Justice (2012) ${ }^{2}$ la idea de la propiedad colectiva de la tierra articulando una teoría que ha aplicado a una serie de temas de justicia global, entre los que se encuentra la inmigración. En este artículo examinaré la plausibilidad de fundar una posición normativa respecto a la inmigración recurriendo a su interpretación de la propiedad colectiva de la tierra. Procederé en cuatro pasos. Primero, me referiré a la consideración del origen del vínculo normativo. Después, a la propiedad colectiva de la tierra en la interpretación particular de Risse, esto es, como propiedad común de la tierra (common ownership of the earth; en adelante: PCT) y a sus consecuencias en el caso de la inmigración. En tercer lugar, desarrollaré cuatro críticas a su teoría y a sus consecuencias para la inmigración. Finalmente, me referiré someramente a un modo alternativo de enfrentar normativamente el fenómeno de la inmigración que no se basa en la PCT, sino en el igualitarismo de la suerte.

\section{Fundamentos relacionales y no-relacionales de la justicia}

Risse denomina su teoría como internacionalismo pluralista ${ }^{3}$. El pluralismo refiere aquí al reconocimiento de diferentes fundamentos, no subsumibles entre sí, de la justicia, que aplicarian a diferentes grupos de personas. Así, se acepta la validez tanto de fundamentos relacionales como no-relacionales en diferentes contextos y entre diferentes grupos de individuos. Este posicionamiento es relevante en los debates sobre justicia global.

\footnotetext{
1 Para una interpretación de la teoría kantiana de la posesión común de la tierra y sus consecuencias en el caso de los refugiados, $c f$. Loewe, D., "Los náufragos de nuestro tiempo. El caso de los refugiados", en: Arbor, v. CLXXXVI, 744 (2010), pp. 555-570.

2 Risse, M., On Global Justice, Princeton: Princeton University Press, 2012.

3 Para una consideración crítica de este posicionamiento de Risse, $c f$. Arneson, R., "Against Relationalism in Global Justice”, en: Ethics \& International Affairs, v. XXVIII, 4 (2014), pp. 477-487.
} 
Inmigración, propiedad común de la tierra e igualitarismo de la suerte global

Un fundamento de justicia no-relacional relaciona la validez normativa a alguna propiedad independiente del tipo de relación entre los agentes. Una propiedad usual en la literatura cosmopolita es la humanidad común ${ }^{4}$. Ser un ser humano (o un ser racional, o tener la capacidad de formar actitudes proposicionales, o un ser sensitivo, etcétera) sería razón suficiente para ser un sujeto de justicia, ya sea como agente o como paciente (es decir, como receptor directo de las obligaciones de los otros ${ }^{5}$ ). Un fundamento de justicia relacional vincula la validez normativa con el tipo de relación o prácticas sociales en que se encuentran los agentes ${ }^{6}$. Estar en una de estas relaciones constituye una razón suficiente para someterse a las exigencias de justicia que la teoría estipule. La identificación del tipo de relaciones y prácticas sociales relevantes admite muchos posicionamientos.

Es usual reconocer la relevancia de vínculos normativos relacionales tales como los parentales, familiares, etcétera. Sin embargo, las relaciones o prácticas sociales pueden delimitar clases más amplias de individuos. John Rawls, por ejemplo, articula una concepción asociacionista estatista, según la cual la consideración de la sociedad como una empresa cooperativa para beneficio mutuo implica exigencias normativas de justicia social ${ }^{7}$ (esto es, la justicia de

4 Loewe, D., "Cinco dimensiones del cosmopolitismo", en: Civitas, v. XV, 4 (2015), pp. e155-e173.

5 La distinción entre agentes morales y pacientes morales permite incluir seres sin agencia moral, tales como ciertos animales no humanos, en la clase de aquellos a los que refieren los principios de justicia, como receptores directos de las obligaciones de terceros. La utilización de este uso conceptual en los debates sobre derechos de los animales se encuentra originalmente en Regan (The Case for Animal Rights, Londres: Routledge, 1984). Un análisis de esta distinción en las teorias contractuales en Loewe ("Inclusión de animales no-humanos en un marco de argumentación teórico contractual”, en: Veritas, v. LIII, 1 (2008), pp. 145-162).

6 Este tipo de enfoque es común en el mundo comunitarista, $c f$. Sandel, M., Liberalism and the Limits of Justice, Cambridge: Cambridge University Press, 1982; Sandel, M., Justice: What's the Right Thing to Do?, Nueva York: Farrar, Strauß and Giroux, 2010; Walzer, M., Spheres of Justice, Nueva York: Basic Books, 1984; Miller, D., On Nationality, Oxford: Oxford University Press, 1995. Una discusión crítica en Loewe, D., "Liberalismo, inmigración y justicia global: Obligaciones especiales hacia nuestros conciudadanos", en: Isegoria, 43 (2010), pp. 435-458.

7 Rawls reconoce también como una propiedad suficiente para ser sujeto de justicia la posesión de las dos capacidades morales (two moral powers) (Rawls, J., A Theory of Justice, Cambridge, Mass.: Harvard University Press, 1971; Rawls, J., Political Liberalism, Nueva York: Columbia University Press, 1993). Así, su liberalismo igualitario (sin cualificaciones relacionales mediadas por la ciudadanía compartida) admite interpretaciones globalistas no relacionales -que él ciertamente rechaza- que extienden los vínculos de justicia a todos los seres humanos en tanto las poseen (Pogge, T., Realizing Rawls, Ithaca: Cornell University Press, 1989; Beitz, C., Political Theory and International Relations. With a New Afterword by the Author, Princeton: Princeton University Press, 1999 (1979); Barry, B., The Liberal Theory of Justice, Oxford: Oxford University Press, 1972; Caney, S., "Cosmopolitan Justice and Equalizing Opportunities", en: Metaphilosophy, 32 (2001), pp. 113-134; Caney, S., "International Distributive Justice", en: Political Studies, v. XLIX, 5 (2001), pp. 974-997). Una discusión en Loewe ("Inmigración y el derecho de gentes de John Rawls. Argumentos a favor de un derecho a movimiento sin fronteras", en: Revista de Ciencia Politica ${ }_{\diamond}$ v. XXVII, 
las instituciones sociales más importantes que componen la estructura básica de la sociedad), que aplican a los ciudadanos en cuanto sujetos libres e iguales que se deben una justificación mutua de los principios institucionales que guian su actuar. La relevancia de la igualdad se sigue de la igualdad democrática de los miembros de la sociedad ${ }^{8}$. De este modo, la relación ciudadana implica ciertas obligaciones de justicia. Sin embargo, dado que a nivel internacional no se darian este tipo de relaciones, su teoría de las relaciones internacionales no reconoce principios globales de justicia distributiva, sino solo una lista bastante disminuida de derechos humanos9.

Otra estrategia relacional es otorgar a la nacionalidad compartida un valor normativo particularista que se asienta en la identidad nacional común ${ }^{10}$. David Miller, conocido defensor de esta posición, desprende de esta relación obligaciones de justicia que reclaman prioridad por sobre las obligaciones de justicia hacia no-connacionales -que, de un modo restringido, él también reconoce ${ }^{11}$. Desde esta perspectiva, la parcialidad hacia nuestros connacionales no es solo admirable, sino una obligación de justicia ${ }^{12}$.

Dependiendo del punto de vista que se asuma (relacional o no-relacional) se siguen consecuencias relevantes para la justicia global. Como vimos, autores que reducen el vínculo normativo al tipo de relación, asociación o práctica social, suelen asumir que la ciudadanía o la nacionalidad implican obligaciones diferentes y más exigentes que aquellas que se siguen de alguna propiedad no-relacional ${ }^{13}$. Autores no-relacionales, por su parte, suelen extender la clase de individuos entre los cuales aplican las exigencias fuertes de justicia a todos

2 (2007), pp. 23-48; "Inclusión de animales no-humanos en un marco de argumentación teórico contractual" y "Cuán liberal es la teoría de las relaciones internacionales de Rawls", en: Veritas, v. LX, 1 (2015), pp. e1-e35). Volveré sobre las dos capacidades en la última sección.

8 Cf. Rawls, J., Justice as Fairness. A Restatement, Cambridge, Mass.: Belknap Press, 2001, p. 49; Rawls, J., A Theory of Justice, pp. 65-66.

9 Rawls, J., The Law of Peoples, Cambridge, Mass.: Harvard University Press, 1999. Una discusión se halla en Loewe, D., "Cuán liberal es la teoría de las relaciones internacionales de Rawls".

${ }^{10}$ Miller, D., On Nationality. Una discusión en Loewe, D., "Liberalismo, inmigración y justicia global: Obligaciones especiales hacia nuestros conciudadanos".

$400 \quad{ }_{11}$ Miller, D., National responsibility and Global Justice, Oxford: Oxford University Press, 2007.

12 Esta idea es común en los posicionamientos comunitaristas frente a la inmigración, como el defendido por Walzer (Spheres of Justice). Para un posicionamiento no-relacional pero identitario, cf. Kymlicka, W., Multicultural Citizenship. A Liberal Theory of Minority Rights, Oxford: Clarendon Press, 1995. Una bibliografia y discusión de estas posiciones en Loewe, D., "La justicia de la inmigración: algunos modelos argumentativos", en: Civitas, v. IX, 3 (2009), pp. 496-513.

${ }_{13}$ No se trata de una relación necesaria: se puede reconocer relaciones relevantes a nivel internacional o global, que impliquen consideraciones distributivas de justicia global, como lo hace Pogge (World Poverty and Human Rights, Cambridge: Polity Press, 2002; “¿Qué es la justicia global?”, en: Revista de Economía Institucional, v. X, 19 (2008), pp. 99-114). 
aquellos que comparten la propiedad no-relacional, incluyendo así consideraciones de justicia distributiva global ${ }^{14}$, como principios de movilidad libre o politicas de fronteras abiertas ${ }^{15}$.

El internacionalismo pluralista de Risse acepta tanto fundamentos de justicia no-relacionales como relacionales, pero delimita su validez a contextos diferentes. Por una parte, a nivel estatal reconoce como fundamentales la reciprocidad y la relación coactiva de los ciudadanos frente al Estado, defendiendo principios de justicia distributiva de tipo rawlsiano. Por otra parte, la igualdad de oportunidades rawlsiana, expresada mediante el principio de la Igualdad Justa de Oportunidades y el Principio de la Diferencia, no sería válida a nivel internacional o global entre individuos que no comparten la ciudadanía. En este caso, serian válidos los fundamentos no-relacionales, que fundan demandas de justicia menos exigentes en comparación a aquellas que se remiten a las relaciones entre ciudadanos ${ }^{16}$. Los fundamentos de justicia no-relacionales refieren a la humanidad común y a la $\mathrm{PCT}^{17}$. En ambos casos se identifica una propiedad no-relacional para establecer principios de justicia que gobiernen las relaciones entre los agentes. En la próxima sección, examinaré la PCT considerando la inmigración.

\section{Propiedad común de la tierra e inmigración}

La interpretación de la PCT de Risse sigue, de un modo no religioso, la teoría de derecho natural de Grocio. Risse asume como punto de partida argumentativo una condición original prepolitica: la propiedad colectiva de la tierra (que él especifica como propiedad común). Esta cumple al menos tres funciones

\footnotetext{
${ }^{14}$ Caney, S., "Cosmopolitan Justice and Equalizing Opportunities"; Caney, S., "International Distributive Justice"; Tan, K., Justice, Institutions, and Luck, Oxford: Oxford University Press, 2012; Moellendorf, D., Cosmopolitan Justice, Oxford: Westview Press, 2002.

${ }^{15}$ Carens, J., "Aliens and Citizens. The Case of Open Borders", en: Review of Politics, v. XLIX, 2 (1987) pp. 251-273; Carens, J., The Ethics of Immigration, Oxford: Oxford University Press, 2013; Cavallero, E., "An Immigration-Pressure Model of Global Distributive Justice”, en: Politics, Philosophy \& Economics, v. V, 1 (2006), pp. 97-127; Loewe, D., "Inmigración y el derecho de gentes de John Rawls. Argumentos a favor de un derecho a movimiento sin fronteras"; Loewe, D., "Obligaciones de justicia: ¿Open Borders o justicia Distributiva?”, en: Arbor, v. CLXXXVIII, 755 (2012), pp. 475-488; Velasco, J.C., El azar de las fronteras, México D.F.: FCE, 2016.

${ }^{16}$ Según Risse: "Morally arbitrary disadvantages are not always unacceptable. Not every disadvantage on the basis of one's nation of birth is problematic. Global equality of opportunities is not morally required" (Risse, M., On Global Justice, p. 164).

17 Con mayor exactitud, Risse reconoce cinco fundamentos de justicia: membrecía compartida en un Estado, humanidad común, propiedad común de la tierra, membrecía en el orden global, participación en el sistema de comercio global. Humanidad común y propiedad común son fundamentos de justicia no-relacionales. Los otros tienen elementos relacionales.
} 
que, a su vez, articulan su teoria ${ }^{18}$ : (i) es una condición de justificación: ser un copropietario implica una posición simétrica frente a los otros y, por tanto, una demanda legítima para ser considerado; (ii) de ella se desprenden derechos naturales (iii) que implican restricciones a las prácticas jurídico-políticas.

El primer aspecto es central: a diferencia de estrategias iusnaturalistas que fácilmente caen en algún tipo de parroquialismo al describir el contexto prepolitico mediante asunciones de la naturaleza humana que se retrotraen a posicionamientos metafísico-culturales, la propuesta de Risse asume un punto de partida prepolítico meramente formal: la simetría de los seres humanos en relación al planeta ${ }^{19}$. Más específicamente: en relación al hábitat como fuente de recursos originales (no producidos por el hombre) necesarios para la satisfacción de necesidades básicas. Evidentemente, la premisa de posesión o propiedad original (Risse reconoce las dificultades terminológicas para referir a esta propiedad pre-politica ${ }^{20}$ ) no se entiende en sentido histórico, sino sistemático. La propiedad colectiva admite múltiples interpretaciones. Risse opta por una interpretación suficientarista: la copropiedad original de la tierra implica igualdad de oportunidades para satisfacer las necesidades básicas con recursos comunes originales ${ }^{21}$. Esto es un principio de oportunidad definido mediante necesidades básicas: dado que espacios y recursos naturales son valiosos y necesarios para la vida humana, y que la satisfacción de necesidades básicas es moralmente importante, cada persona tiene un derecho natural a satisfacer sus necesidades básicas mediante los recursos y espacios originales. Las necesidades básicas son interpretadas de un modo minimalista en relación con la

\footnotetext{
18 Stilz, A., "On Collective Ownership of the Earth", en: Ethics \& International Affairs, v. XXVIII, 4 (2014), pp. 501-510.

${ }^{19}$ Cf. Alvarez, D., "Propiedad común de la tierra, Derechos humanos y justicia global", en: Isegoria, 43 (2010), p. 388.

20 En mi opinión, estas dificultades terminológicas están incorrectamente resueltas por el autor. La relación hacia un objeto exterior en status naturalis debe ser caracterizada como posesión y no como propiedad (como lo hace Kant; compare, entre muchos, Horn, C., Nichtideale Normativität, Fráncfort d. M.: Suhrkamp, 2014, cap. 4; Loewe, D., "Libertad y propiedad en la fundamentación 402 del Estado kantiano”, en: Ormeño, J. y M. Vatter (eds.), Forzados a ser libres. Kant y la teoría republicana del derecho, México D.F.: FCE, 2017). Sin embargo, aunque no sea así, antes de un acto de apropiación (en status naturalis) la referencia a la propiedad común carece de un sentido preciso. No discutiré este uso terminológico y supondré que la referencia a la propiedad común de la tierra (anterior al exeundum) puede tener algún sentido jurídico para la obtención de consecuencias teóricas distributivas, como asume Risse.

${ }^{21}$ Risse rechaza la interpretación de Joint Ownership y de Private Ownership debido a las exigencias de su institucionalización. La primera exige un mecanismo institucional consultivo de todos los copropietarios para aprobar cualquier uso que se haga de la joint ownership. La segunda supone que todos tienen un derecho a una cantidad idéntica de recursos.
} 
salud fisica y mental, así como a la posesión de las competencias para elegir y deliberar. Esta interpretación es lo que él denomina PCT.

La teoría implica derechos de libertad, demandas y un derecho de inmunidad $^{22}$. El acceso a los recursos comunes exige la aceptación simétrica por parte de los otros de no interferir en este en tanto se trate de la satisfacción de necesidades básicas. Se trata, por ende, de un derecho de libertad para apropiarse de recursos al que se asocia una demanda (claim right) cuando la apropiación refiere a la satisfacción de necesidades básicas. Más allá de su satisfacción, lo que queda se asemeja a un estado de naturaleza hobbesiano. Así, y este es el segundo aspecto de la referencia sistemática a PCT, se derivan de ella derechos humanos (conceptualizados como derechos naturales) que, de acuerdo a la especificación mediante la satisfacción de necesidades básicas, corresponden a una concepción acotada de los mismos, como derechos especialmente importantes. En tercer lugar, la PCT implica un derecho de inmunidad de todo copropietario contra cualquier ordenamiento jurídico social incompatible con esta copropiedad original, asegurando así restricciones a las prácticas político-jurídicas a través del tiempo.

Los destinatarios de estas demandas, específicamente del derecho de inmunidad (que asegura restricciones a las prácticas politico-jurídicas), son los Estados, además de los organismos internacionales y las instituciones del Bretton Woods (Banco mundial, OMC). En la actualidad el mundo habitable está dividido entre Estados que reclaman jurisdicción sobre territorios y recursos, así como control sobre flujos comerciales y migratorios. De este modo, el sistema de Estados influye directamente en el acceso a recursos originales de los individuos e interfiere directamente en la oportunidad de los copropietarios de satisfacer sus necesidades básicas. Los copropietarios tienen, por tanto, un derecho de inmunidad cuyos destinatarios son los Estados y otras organizaciones del orden global, para que la demanda de satisfacción de necesidades básicas mediante recursos originales sea respetada. La legitimidad del orden global depende del cumplimiento de esta condición. Evidentemente, esta teoría tiene múltiples implicaciones. En lo que sigue, me referiré a sus consecuencias en el caso de la inmigración.

\footnotetext{
22 Sucesivamente: liberty rights, claim rights e immunity rights. Risse refiere al análisis clásico de derechos de Hohfeld ("Fundamental Legal Conceptions", en: Cook, W. (ed.), Fundamental Legal Conceptions as Applied in Judicial Reasoning, and Other Legal Esays, by Wesley Newcomb Hohfeld, New Haven: Yale University Press, 1919).
} 


\subsection{Teoría ideal y teoría no-ideal}

La teoria de justicia global de la PCT estipula que la legitimidad de las convenciones de propiedad depende de la satisfacción de las necesidades básicas. Estas convenciones deben (i) garantizar a los copropietarios la oportunidad para utilizar los recursos originales de la tierra para satisfacer necesidades básicas, o (ii) garantizar la oportunidad para satisfacer necesidades básicas de otros modos. Se trata de una exigencia de justicia. En el caso de la inmigración hay que diferenciar dos situaciones. En la primera, las necesidades básicas de algunos copropietarios no son satisfechas; en la segunda, ellas sí lo son.

La pregunta acerca de qué hacer en casos en que la condición de satisfacción de necesidades básicas no se cumple es parte de una teoría de justicia no-ideal. En este caso, la teoría de justicia global aspira a que las necesidades básicas de los copropietarios sean satisfechas alli donde se encuentren: "It is part of my proposal that the response required to scenarios in which individuals cannot satisfy basic needs is to make sure they can do so where they live, rather than permit immigration for that reason"23. Por lo tanto, la demanda de justicia efectiva en casos de no satisfacción de necesidades básicas no es, primeramente, una restricción a la potestad de los Estados para excluir inmigrantes que aspiren a ingresar para satisfacerlas mediante los recursos originales comunes, sino que es una demanda para que se garantice la oportunidad de satisfacerlas en el lugar en que se encuentren los copropietarios. Sin embargo, es fácil notar que, si esto no es posible, puede surgir una demanda legítima expresada en términos de justicia para que no se excluya a los inmigrantes con necesidades básicas insatisfechas. Este puede ser el caso, por ejemplo, de los habitantes de las islas destinadas a desaparecer producto del aumento del nivel de los mares que trae consigo el calentamiento global ${ }^{24}$. Sin embargo, también podría ser el caso de copropietarios con necesidades básicas que no pueden ser satisfechas en sus países de origen, como los refugiados. En estos casos acotados, la teoría tiene un rendimiento positivo con respecto a la inmigración. Se trata, no obstante, de preguntas de una teoría no-ideal de justicia, de un tipo de preguntas que no están en el foco de On Global Justice.

\footnotetext{
23 Risse, M., On Global Justice, p. 153.

24 En otro sitio, Risse ha sostenido que "the inhabitants of Kiribati, like all human beings, are co-owners of the earth and as such have claims to relocation in the event that their existence becomes impossible where they presently live and regardless of who was responsible for creating this situation" (Risse, M., "The Right to Relocation: Disappearing Island Nations and Common Ownership of the Earth", en: Ethics \& International Affairs, v. XXIII, 3 (2009), p. 282).
} 
Así se presenta la segunda situación, que corresponde a la teoría ideal de justicia (es decir, en términos rawlsianos: una teoría de cumplimiento perfecto): asumiendo que las necesidades básicas de todos los copropietarios son satisfechas, ¿qué se sigue del enfoque de la propiedad común en el caso de la inmigración? Risse responde a esta pregunta mediante una teoría de uso proporcional (proportionate use), según la cual hay que examinar si los Estados están subutilizando o sobreutilizando los recursos originales en comparación con los otros Estados. La idea es la siguiente: para cada Estado hay una medida del valor de los recursos originales de propiedad colectiva dentro de su territorio y este valor incluye las condiciones biofisicas que determinan la utilidad de esta región para propósitos humanos (tales como clima, vegetación, ubicación, topografia, etcétera). Al dividir este valor por la población de ese territorio se obtiene la medida de uso de este territorio expresada como la tasa de uso per cápita de los recursos de propiedad común en ese territorio. El valor incluye recursos que no circulan en el mercado, tales como minerales o recursos no explotados. Para posibilitar la comparación de la tasa de uso per cápita entre diferentes Estados, Risse recurre a una medida unidimensional como un precio de mercado mundial. La tasa de uso per cápita de cada Estado, expresada mediante una medida unidimensional, se compara así con la tasa de uso per cápita promedio a través de los Estados. Si el valor es mayor que el promedio a través de los Estados, entonces el territorio del Estado está, relativamente, siendo subutilizado; si el valor es menor, entonces está, relativamente, siendo sobreutilizado. Expresado de otro modo: cuando un Estado subutiliza sus recursos, entonces la persona promedio en ese Estado usa un paquete de recursos de mayor valor que la persona promedio en el país promedio; cuando un Estado sobreutiliza sus recursos, entonces la persona promedio usa un paquete de recursos de menor valor que la persona promedio en el país promedio. Según la teoría del uso proporcional, si el valor "is above average, co-owners elsewhere have a pro tanto claim to immigration, in the sense that underusing countries cannot reasonably expect other to comply with immigration policies until such claims are satisfied"25. Esto vale hasta que la tasa de uso promedio de los Estados se asemeje. Según Risse, los Estados que subutilizan pueden pagar en vez de aceptar la entrada de extranjeros. Sin embargo, si los inmigrantes -en tanto copropietarios de los recursos comunes- prefieren entrar, los Estados no pueden descargar su obligación pagando.

${ }^{25}$ Risse, M., On Global Justice, p. 154. 


\section{Ciudadanos del mundo como copropietarios de la tierra}

La teoría de la PCT invita a considerar el sistema de relaciones internacionales desde la perspectiva de relaciones de propiedad. En cierto sentido, el ciudadano del mundo de las teorías cosmopolitas ${ }^{26}$ es caracterizado aquí como un copropietario de los recursos originales del planeta. Si bien esta teoría es atractiva e intelectualmente exigente, no es capaz de dar cuenta satisfactoriamente de las demandas normativas relacionadas con la inmigración. A continuación, consideraré cuatro tipos de dificultades.

\section{1 Desigualdad económica e inmigración}

La teoría no reconoce como normativamente relevantes las causas a la base de parte importante de los flujos migratorios y, así, no puede articular una respuesta plausible al fenómeno de la inmigración. Vivimos en un mundo caracterizado por grandes desigualdades. En términos del Coeficiente de Gini, la desigualdad global es mayor que la desigualdad dentro de cualquier país singular. Según Branko Milanovic ${ }^{27}$, economista del Banco Mundial, esto se debe a que, a comparación del siglo XIX, en que la mayor diferencia de ingreso entre individuos era atribuible a su posición en la sociedad, hoy refiere al país del que se es ciudadano. En una medida importante, son estas desigualdades las que están a la base de los flujos migratorios. Inmigrantes económicos -que componen la mayor parte de estos flujos- buscan mejores oportunidades de vida. En un mundo organizado mediante Estados, no es previsible que esta migración y los desafios institucionales que conlleva se vean aminorados o, al menos, encauzados institucionalmente mediante un derecho que garantice que el sujeto no sea rechazado al cruzar las fronteras cuando se requiere el acceso a los recursos originales para satisfacer necesidades básicas, como exige la PCT.

Hay que tener presente que la conceptualización de Risse de los derechos básicos es minimalista. Ellos se definen en relación a la salud física y mental, así como a la posesión de las competencias para elegir y deliberar. Así intenta generar, correctamente en mi opinión, una concepción no controvertida de necesidades básicas, evitando elementos culturales o idiosincráticos. No obstante, mientras menos exigente sea la definición de necesidades básicas, el espacio

\footnotetext{
${ }^{26}$ Sobre el concepto de ciudadanía cosmopolita, compare Loewe, D., "Cuán liberal es la teoría de las relaciones internacionales de Rawls".

${ }^{27}$ Milanovic, B., Global inequality. A new Approach for the Age of Globalization, Cambridge, Mass./Londres: Belknap Press, 2016.
} 
no cubierto por el derecho a no ser rechazado al cruzar fronteras será mayor y así también la presión migratoria que la teoría no cubre.

Un simil con la teoría de las relaciones internacionales de Rawls es ilustrativo. Rawls argumenta que si se realiza su utopía realista y, correspondientemente, todos los pueblos y sociedades llegan a ser bien-ordenados, la inmigración no sería un fenómeno relevante ${ }^{28}$. Sin embargo, esta tesis no es convincente. Su teoría de las relaciones internacionales no reconoce ningún principio de justicia distributivo global ${ }^{29}$ y no puede contrarrestar la desigualdad económica. Ya que esta es la mayor causa de la inmigración, esta continuaría siendo un elemento de presión en su utopía realista ${ }^{30}$. Risse es ciertamente más moderado. Por una parte, no supone que la inmigración dejaría de ser un fenómeno relevante si su teoría de justicia global fuese efectiva; por otra, su concepción de necesidades básicas, cuya satisfacción es un asunto de justicia, a pesar de ser limitada, es más exigente que la rawlsiana con su concepción minimalista de los derechos humanos. Sin embargo, de un modo similar a Rawls, una vez que su teoría ideal se ha implementado y, por tanto, las necesidades básicas de los copropietarios han sido satisfechas, él no considera relevante las desigualdades económicas. En este mundo, tal como en el de la teoría rawlsiana de las relaciones internacionales, aún habría muchos individuos intentando cruzar fronteras para mejorar sus condiciones de vida, incluso cuando sus necesidades básicas estén satisfechas. Como examinaré en la próxima sección, lo que la teoría de Risse tiene para ofrecer en este caso -una demanda de conducta razonable- es sustantivamente insípido.

\subsection{Justicia versus demandas de conducta razonable}

De acuerdo a la teoria de uso proporcional, países que subutilizan recursos originales no pueden rechazar inmigrantes de países que los sobreutilizan. Sin cualificar, esta posición implicaría que los Estados deberían tener un control selectivo de los inmigrantes para que ingresen aquellos que provienen de Estados que efectivamente sobreutilizan, hasta que se igualase la tasa de uso a través de los países. Esta posición está más cerca de la que Risse parece sostener en artículos antiguos. Así, en On the Morality of Immigration, luego

\footnotetext{
${ }^{28}$ Rawls, J., The Law of Peoples, p. 9.

${ }^{29}$ Como es conocido, Rawls sostiene una obligación de asistencia, pero la diferencia tajantemente de una obligación de justicia distributiva global. Una discusión en Loewe ("Cuán liberal es la teoria de las relaciones internacionales de Rawls").

${ }^{30}$ Nussbaum, M., Frontiers of Justice, Harvard: Harvard University Press, 2006.
} 
de reconocer que la suya no es una teoría que justifique fronteras abiertas, afirma: "What it does say is that as long as a country underuses its resources and refuses to permit more immigration in response, illegal immigration cannot be morally condemned"31. Según Risse, los inmigrantes ilegales potenciales no tienen ninguna razón para respetar las restricciones migratorias impuestas por un Estado que subutiliza. Ellos no están haciendo "anything morally wrong -provided they merely wished to become regular participants in society and abide by its laws from then on"32. De aquí solo habría un paso a afirmar que Estados que subutilizan deberían, por razones de justicia, abrir sus fronteras a los inmigrantes potenciales de países que sobreutilizan ${ }^{33}$. Si se diese este paso, el control de las fronteras de los países que subutilizan estaría fuertemente restringido por razones normativas. Sin embargo, sin cualificaciones, esta interpretación estaría en tensión con el entendimiento de la PCT. Como vimos, este es suficientarista, es decir, la PCT es fuente de demandas de justicia en la medida en que se trate de satisfacer necesidades básicas. Si los inmigrantes potenciales pudiesen aducir razones de justicia en razón del estatus de subutilización del Estado al que desean ingresar, entonces sería el uso proporcional de los recursos comunes y no la satisfacción de necesidades básicas mediante recursos comunes lo que caracterizaría a la propiedad común. Estos dos elementos están en tensión: si la demanda de justicia depende de la segunda interpretación, entonces no aplica a la primera; si depende de la primera, entonces la segunda es irrelevante.

La solución de este problema, y su toma de posición, se encuentra en On Global Justice. Dado que se trata de una teoria ideal, sostiene que la demanda de justicia para la satisfacción de necesidades básicas que se sigue de la propiedad común mediante recursos originales ya ha sido satisfecha dentro de los Estados singulares. Las obligaciones que se siguen de la teoría del uso proporcional no serian obligaciones de justicia, sino demandas de conducta razonable. Según Risse, las obligaciones de justicia referirian a exigencias normativas especialmente importantes, cuyo cumplimiento puede ser exigido. 408 Este sería el caso de las que refieren a la satisfacción de necesidades básicas.

\footnotetext{
${ }^{31}$ Risse, M., "On the Morality of Immigration", en: Ethics \& International Affairs, v. XXII, 1 (2008), pp. 30-32.

${ }_{32}$ Ibid, pp. 30-32.

${ }^{33}$ Esta interpretación se ha utilizado para criticar la teoria, ya que se seguiría la pérdida de legitimidad para controlar las fronteras en caso de Estados que subutilizan (cf. Oberman, M., "Immigration, Global Poverty and the Right to Stay", en: Political Studies, v. LIX, 2 (2011), pp. 253-268). Esta es, sin embargo, una interpretación incorrecta.
} 
No obstante, si bien es razonable que los Estados que subutilizan no establezcan políticas que rechacen a los inmigrantes potenciales provenientes de Estados que sobreutilizan, esto no sería exigible como un asunto de justicia.

Risse suele ilustrar este punto con un experimento mental ${ }^{34}$ : imaginemos que la población de EEUU se reduce a dos o tres individuos que mediante un sistema tecnológico avanzado pueden controlar las fronteras. Evidentemente, se trataría de un caso de subutilización de recursos naturales. En este caso habría una demanda de conducta razonable hacia ellos para que permitan el ingreso de inmigrantes de países que sobreutilizan. Sin embargo, ya que no se trata de una demanda de justicia (porque las necesidades básicas de los copropietarios ya han sido satisfechas), no se puede exigir que los dejen entrar. De igual modo, no se puede exigir a los inmigrantes potenciales que no intenten acceder al territorio. Esto sería una demanda de conducta irrazonable. Así, estos pueden intentar ingresar y los primeros intentar evitarlo. Según Risse, mientras no se utilice violencia y, por tanto, no se violen los derechos de los involucrados, no se ha violado ninguna demanda de justicia; "[n]onetheless, there is something problematic about this scenario of the three Americans keeping the country to themselves even though the wrongness is not an injustice. The wrongness consists in doing something unreasonable, and what's unreasonable is the lack of proportionality"35. Los Estados que subutilizan y tratan de impedir la inmigración han violado una demanda de conducta razonable.

Es dificil entender qué es una demanda de conducta razonable. Sin embargo, es aun más insatisfactoria la ausencia de sus bases normativas. Risse dice muy poco al respecto. En una nota al pie ${ }^{36}$ afirma que se trataría de apelaciones similares a obligaciones de beneficencia imperfectas, siempre subordinadas a exigencias de justicia. En su interpretación, que él mismo considera insuficiente, esto significa que (i) tendrian una diferencia de grado con las obligaciones de justicia -serían más débiles-y (ii) su foco sería la obligación y no el derecho moral correspondiente que la humanidad colectivamente sí poseería.

Primero, de la definición de la demanda de conducta razonable no se sigue que sea una demanda en sentido estricto. Siguiendo el análisis de Bull, se trataría de "a demand of reasonable conduct on person $\mathrm{P}$ to perform action $\mathrm{A}$ if and only if it would be unreasonable for $\mathrm{P}$ not to do A, and if and only if $\mathrm{P}$

\footnotetext{
${ }^{34}$ Risse, M., On Global Justice, cap. 8; Risse, M., "Response to Arneson, de Bres, and Stilz", en: Ethics \& International Affairs, v. XXVIII, 4 (2014), pp. 511-522. Una ilustración ligeramente diferente en Risse, M., "On the morality of Immigration".

${ }^{35}$ Risse, M., "Response to Arneson, de Bres, and Stilz", p. 521.

${ }^{36}$ Risse, M., On Global Justice, pp. 382-383.
} 
can reasonably be expected to do A"37. Asi, por ejemplo, sería una demanda de conducta razonable hacia Mary que ayude a John, si y solo si, no es razonable para Mary no ayudar a John, y si y solo si puede ser razonablemente esperado de Mary que ayude a John. Sin embargo, la conjunción entre "ser no razonable no hacer A" y la "razonable expectación de que haga A" no constituye por sí misma una demanda para que se haga $A^{38}$. Para que sea una demanda, es decir, una exigencia normativa para realizar (o no realizar) una acción, hay que dar cuenta del origen normativo de esta exigencia.

Segundo, si la interpretación de la propiedad común relevante es la que relaciona el estatus de los copropietarios con la satisfacción de necesidades básicas, no es evidente de dónde obtiene su reclamada fuerza normativa la teoría del uso proporcional. Es claro que las demandas normativas pueden tener diferentes grados de importancia, lo que se puede relacionar con su exigibilidad $^{39}$, además del hecho de que su enfoque es pluralista. A pesar de ello, si bien hay buenas razones para tener acercamientos normativos pluralistas, el pluralismo no se puede extender al punto en que se conceptualiza la PCT de dos modos diferentes, esto es, como un derecho de los copropietarios a satisfacer sus necesidades básicas con los recursos originales comunes y, simultáneamente, como una exigencia de proporcionalidad en la utilización de los recursos originales comunes ${ }^{40}$.

La interpretación de la propiedad común de Risse no explicita la relevancia normativa de la falta de proporcionalidad. Hacer descansar toda esta estructura teórica en la afirmación de que desarrollar una teoría de conducta razonable "would require adding more foundational moral theory than would be sensible to include in the project this book is engaged in" 41 es lo mismo

37 Bull, M., "Help Yourself", en: London Review of Books (2013) (https://www.lrb.co.uk/v35/ n04/malcolm-bull/help-yourself

38 Cf. ibid.

39 Cf. Risse, M., "Response to Arneson, de Bres, and Stilz".

40 Un modo de afirmar ambos principios simultáneamente podría articularse sosteniendo que la primera conceptualización (copropiedad como satisfacción de necesidades básicas mediante recursos comunes no producidos por el hombre) refiere a los ciudadanos del mundo en tanto copropietarios, mientras que la segunda (copropiedad como exigencia de conducta razonable) a los Estados en tanto copropietarios. Esta interpretación es posible, pero ella implica establecer una diferencia normativa fuerte entre individuos y Estados. Si bien parece razonable argumentar desde una perspectiva cosmopolita que el derecho individual que se basa en la satisfacción de necesidades básicas pesa más que el derecho de Estados a excluir, no parece ser razonable desde esta perspectiva que el derecho de los Estados a excluir pese más que la demanda de los individuos frente a los Estados para que permitan su ingreso en caso que subutilicen recursos naturales. En todo caso, esta no es la interpretación de Risse.

41 Risse, M., On Global Justice, p. 383. 
que, inversamente, reconocer que esta demanda no encuentra bases teóricas en este libro. Sin embargo, reconocer esta carencia no exculpa a la teoría de la incapacidad teórica que en ella produce, sino lo contrario. Esta incapacidad es seria: las demandas de conducta razonable que la teoria estipula, y a las que otorga un sitio central en la estructura argumentativa, carecen de bases normativas en la idea de la PCT.

Tercero, limitar la legitimidad de la inmigración a casos de satisfacción de necesidades básicas parece ser una interpretación extremadamente limitada de la propiedad colectiva. En definitiva, lo que implica la PCT es "a residual right of necessity, much like what Grotious also recognized"42. Si esto es así, entonces se trataría de un derecho a violar los derechos de los otros -o una restricción de los derechos de los otros- cuando se trata de preservar la propia vida o, según la interpretación de Risse, de satisfacer necesidades básicas (y esa restricción es el único modo de lograrlo). Es el derecho de necesidad el que impone límites a las convenciones vigentes sobre la propiedad legítima. Al confrontar esto con las condiciones de pobreza de nuestro mundo, lo que la teoria sustantivamente rinde no es poco. No obstante, reducir las consideraciones normativas acerca de la justicia distributiva global, o acerca del derecho a movilidad, a interpretaciones del derecho de necesidad no es atractivo. Consideraciones acerca de la justicia del entramado institucional, ya sean estado-céntricas, internacionales o globales, no son reducibles a consideraciones sobre el derecho de necesidad. No se trata de un asunto de grado. Qué es una distribución justa (cualquiera sea la métrica y el principio distributivo) es una pregunta de un tipo muy diferente a qué permite el derecho de necesidad (que remite a situaciones eminentemente excepcionales). Con otras palabras, consideraciones de justicia distributiva y aquellas que se derivan del derecho de necesidad son cualitativamente diferentes ${ }^{43}$. La interpreta-

\footnotetext{
${ }^{42}$ Risse, M., "Response to Arneson, de Bres, and Stilz", p. 519.

${ }^{43}$ El punto ha sido objeto de controversia. Asi Hont e Ignatieff (Wealth and Virtue, Cambridge: Cambridge University Press, 1983) han recurrido al derecho de necesidad para afirmar que el derecho defendido por Aquino y otros pensadores premodernos para tomar lo que se requiere para sobrevivir, se expresa como una obligación legal de apoyar a los pobres -es decir, el derecho de necesidad sería el antecedente de la justicia social distributiva-. Pero esta es una interpretación errada. Para Aquino el derecho de necesidad es un caso de justicia conmutativa, no de justicia distributiva. Y en esto lo secundan autores como Grocio (por recurso a cuya teoría Risse articula la suya). De hecho, todos estos autores sostienen concepciones extremadamente estrechas del derecho de necesidad y sus implicaciones. Se trata, de un derecho en los casos más dramáticos y de peligro vital inminente a usar lo que se requiere para sobrevivir. Ciertamente es un derecho y no una obligación de benevolencia, pero no es definitorio de la justicia. Fleischacker ha defendido el punto con precision: "The right of necessity is, by definition, an exception to the ordinary course of justice and not a part of that course" (A Short History of Distributive Justice, Cambridge, Mass.: Harvard University Press, 2004 p. 34).
} 
ción kantiana del derecho de necesidad ilustra bien el punto: si bien el derecho de necesidad permite al náufrago quitar a otro náufrago el madero al que se aferra, y así mantenerse a flote, esto se debe a que, según Kant, la amenaza incierta de la pena nunca podría ser más dura que la consecuencia cierta de desistir de quitárselo ${ }^{44}$. Sin embargo, desde la perspectiva de la teoría moral kantiana, es evidente que lo que el náufrago realiza se opone a la ley moral: está utilizando a otro exclusivamente como medio para la consecución de su fin (mantenerse con vida). Expresado de otro modo, el derecho de necesidad establece el carácter no punible de ciertas acciones, pero esto es diferente a establecer la justicia de esas acciones. Puede ser que el derecho de necesidad sea un mínimo sobre el cual se pueda lograr un cierto consenso, pero, nuevamente, no es un consenso acerca de la justicia distributiva, sino sobre lo que no debe ser castigado.

\subsection{Guías de acción y consecuencias inaceptables}

La teoría no solo adolece de falta de guías para la acción, sino que las consecuencias que se siguen de ella son normativamente insostenibles. Según la teoría, la tasa de uso per cápita de recursos naturales originales en un país debería llevar a admitir inmigrantes (como una demanda de conducta razonable). El problema es que esta tasa no se correlaciona con el nivel de riqueza comparativo de ese país o con el nivel per cápita de sus habitantes. De hecho, la riqueza de los países se relaciona mejor con el capital humano y con los recursos hechos por el hombre. Así, la teoría de Risse adolece de irrelevancia práctica ya que no ofrece guías prácticas de acción en vista de las condiciones fácticas del mundo. El mismo Risse reconoce que este podría ser el caso: "To the extent that immigration pressure is generated by income differences, measures of relative over- and under-use cannot track such pressure if the strength of the economy is insignificantly correlated with resource-richness" 45 . Sin embargo, no se trata de una afirmación condicional, como la presenta Risse, sino indicativa: es efectivamente así, como él sostiene que podría ser. Ahora bien, por ello, perseverar en torno a un posicionamiento teórico prácticamente irrelevante (es

412 decir, que ni siquiera sirve como ideal regulativo que bajo condiciones ideales ofrezca guías prácticas para la acción) no parece expresar más que un tipo de rigorismo ajeno al mundo.

\footnotetext{
${ }_{44}^{44}$ Kant, I., Die Metaphysik der Sitten, Akademie-Ausgabe VI (MS), pp. 205-493.

${ }^{45}$ Blake, M. y M. Risse, "Is there a Human Right to Free Movement? Immigration and Original Ownership of the Earth", en: KSG Working Paper No. RWP06-012 (2006), p. 15 (https://ssrn. com/abstract $=902383$ ).
} 
Hay países que subutilizan sus recursos naturales y son ricos. Este sería el caso de los Estados Unidos, al que Risse alude y trata especialmente en relación a los inmigrantes ilegales ${ }^{46}$. En este caso, la presión de los flujos migratorios coincidiría con el espacio de la teoría del uso comparativo. Sin embargo, también hay países que sobreutilizan y son ricos, como Holanda (un ejemplo recurrente de Risse) o Luxemburgo. Además, hay también países con una alta tasa de subutilización, pero que son pobres, como Bolivia. Considerando el Producto Interno Bruto per cápita como aproximación a la riqueza, Luxemburgo supera los 93.000 dólares y Holanda los 48.000, mientras que Bolivia alcanza apenas los 6.400. Es decir, de acuerdo a la teoría del uso comparativo, habría una demanda de conducta razonable hacía Bolivia y otros países que se encuentren en situación similar de subutilización para que permitan el ingreso de inmigrantes provenientes de países como Holanda y Luxemburgo que sobreutilizan sus recursos naturales. Es evidente, sin embargo, que un país pobre como Bolivia no constituye sin más un destino migratorio atractivo. Si no ofrece alguna perspectiva de prosperidad no será objeto de presión migratoria. Es claro, por ende, que la teoría no ofrece guías prácticas relevantes para la acción.

Además, como se discutió en la sección anterior, incluso en los casos en que la teoría coincide con la dirección de los flujos migratorios, se trata solo de una demanda de conducta razonable. Se trata de una demanda más débil que una de justicia y, como podemos suponer en base a su interpretación, una que se sigue de una obligación moral, pero cuyo cumplimiento no es exigible en razón de un derecho correspondiente ${ }^{47}$. Con excepción del recurso a la violencia, los tres norteamericanos de la ilustración pueden hacer todo para impedir el acceso de los inmigrantes potenciales (en tanto sus necesidades básicas estén satisfechas). No sin razón, Malcolm Bull titula su discusión de este libro "Help Yourself"48. Según Bull, lo desconcertante de esta teoría es que -en contraste con lo que su autor supone como su rendimiento normativo- se asemeja a una descripción del mundo tal como es. Esto se debe a que reconoce el derecho de los Estados sobre su territorio y recursos, tal como lo reconoce el sistema internacional en la actualidad. A beneficio de Risse, se debe cualificar esta afirmación por referencia a las necesidades básicas a cuya satisfacción los copropietarios tienen una demanda de justicia. Más allá de esto, a nivel global, la teoría tiene, no obstante, poco que ofrecer a los desposeídos de la tierra (solo una demanda de conducta razonable).

\footnotetext{
46 Risse, M., "On the Morality of Immigration".

47 Risse, M., On Global Justice, pp. 382-383.

48 Bull, M., "Help Yourself".
} 


\subsection{Recursos originales y recursos creados por el hombre}

Las demandas de los copropietarios para la satisfacción de sus necesidades básicas refieren exclusivamente a recursos naturales originales y excluyen los recursos hechos por el hombre y el capital humano. El fundamento de esta distinción es que los recursos y espacios existen con independencia de cualquier acción humana, de modo que nadie puede reclamar derechos especiales sobre ellos. De esta simetría frente a los recursos naturales se sigue la demanda de justicia sobre estos, en la medida que sean necesarios para satisfacer necesidades básicas. Por el contrario, en el caso de los recursos hechos por el hombre y del capital humano, los propietarios son las personas (también en una versión colectiva e intergeneracional) que generaron el valor no natural. La idea es que en este caso hay razones para sostener mérito y, así, la legitimidad de las demandas especiales. Sin embargo, esta distinción es cuestionable.

Parcialmente, esta distinción se asemeja a aquella entre circunstancias y elecciones, corriente entre igualitaristas de la suerte ${ }^{49}$, y a la familiar distinción entre contingencias moralmente arbitrarias y responsabilidad por los propios fines ${ }^{50}$. Risse mismo refiere a ella al realizarla. Esta distinción admite múltiples variantes. Lo importante es que, en algún punto, debe ser posible trazar una línea entre los dos tipos de elementos: suerte y agencia ${ }^{51}$. La relevancia normativa de esta distinción es que no se puede considerar a los individuos como responsables por las consecuencias de las circunstancias no escogidas o por las contingencias moralmente arbitrarias y, por tanto, no se puede exigir que lleven (todos) los costes que se retrotraen a ellas, sino que deben ser neutralizadas, mitigadas o corregidas mediante principios de justicia. Por cierto, Risse funda su teoría en un derecho natural a la satisfacción de necesidades básicas mediante recursos naturales y no en la distinción entre agencia y suerte que subyace al igualitarismo de la suerte. Sin embargo, la distinción relevante entre recursos naturales y recursos hechos por el hombre se basa en lo siguiente: frente a los primeros estamos en una situación simétrica y, correspondientemente, nadie puede presentar demandas especiales; frente a los segundos, aquellos 414 que generaron el valor no natural son los legítimos propietarios porque, en

\footnotetext{
${ }^{49}$ Dworkin, R., "What is Equality? Part 1: Equality of Welfare", en: Philosophy and Public Affairs, v. X, 3 (1981), pp. 185-246 (https://www.jstor.org/stable/2264894); Dworkin, R., "What is Equality? Part 2: Equality of Resources", en: Philosophy and Public Affairs, v. X, 4 (1981), pp. 283-345 (https://www.jstor.org/stable/2265047).

${ }^{50}$ Rawls, J., A Theory of Justice, 1971; A Theory of Justice (revised edition), Cambridge, Mass.: Harvard University Press, 1999.

51 Cf. Tan, K., Justice, Institutions, and Luck.
} 
Inmigración, propiedad común de la tierra e igualitarismo de la suerte global

cierto sentido, lo merecen. Es decir, aunque cualificada de un modo diferente, corresponde a la distinción a la base del liberalismo igualitario.

No obstante, ¿en qué medida son los ciudadanos de un país legítimos propietarios del valor no natural generado y acumulado? Esta pregunta es fundamental y no espero responderla aquí. Según Milanovic, como referí, la mayor diferencia de ingreso se puede atribuir al país del que se es ciudadano. ¿Por qué los holandeses son propietarios legítimos de los recursos hechos por el hombre y el capital humano colectivo al que tienen acceso por nacimiento?

Entre igualitaristas, la distinción entre suerte y agencia sigue una lógica individual: en relación a cada individuo se debe diferenciar entre circunstancias no escogidas y decisiones. Así, el medioambiente socioeconómico original (la riqueza de los padres y las oportunidades que puede o no ofrecer) se considera como no atribuible a la propia responsabilidad. Después de todo, no hemos hecho nada por ello. Se trata de lotería social o suerte bruta. Lo que distingue a los igualitaristas es el espacio de aplicación de esta idea. Mientras los igualitaristas democráticos consideran que el espacio relevante está dado por las sociedades politicamente organizadas y otros igualitaristas de la suerte circunscriben la importancia de la igualdad a estas sociedades, los igualitaristas globales extienden el espacio a toda la humanidad y consideran, por tanto, que circunstancias moralmente arbitrarias tales como el lugar de nacimiento no deberian afectar tan negativamente el acceso a oportunidades ${ }^{52}$. Todos ellos reconocen, a pesar de ello, que se trata de una distinción que refiere a individuos $^{53}$. Por su parte, Risse aplica esta distinción de un modo colectivo: son los ciudadanos de un país los que colectivamente tienen derechos de propiedad,

\footnotetext{
52 Cf. Carens, J., "Aliens and Citizens. The Case of Open Borders", "Cosmopolitan Justice and Equalizing Opportunities", "International Distributive Justice"; Shachar, A., The Birthright Lottery. Citizenship and Global Inequality, Cambridge, Mass.: Harvard University Press, 2009; Velasco, J.C., El azar de las fronteras.

${ }^{53}$ En su teoria de las relaciones internacionales Rawls (The Law of Peoples, 1999a) afirma -como Risse- que los pueblos son propietarios del valor generado. Pero esta afirmación es dificilmente compatible con el igualitarismo que anima su teoria. De cualquier modo, al nivel de las relaciones internacionales Rawls asume, de un modo acrítico el nacionalismo metodológico, lo cual es criticable (Pogge, T., “¿Qué es la justicia global?”) (para sustentar su afirmación de que los pueblos son completamente responsables de sus éxitos y fracasos solo refiere al libro de David Landes, The Wealth and Poverty of Nations). Quizá el mejor argumento de Rawls para defender la idea de que los pueblos y los Estados son completamente responsables de su desarrollo, es que debe haber una asignación territorial de la responsabilidad para que el conjunto de activos no se deteriore. Pero nuevamente, una cosa es afirmar la importancia de una asignación de responsabilidad y otra muy distinta afirmar que los responsables son los pueblos y sociedades existentes, y que esta responsabilidad es completa. Una discusión de estas tesis en Loewe ("Cuán liberal es la teoría de las relaciones internacionales de Rawls").
} 
basado en el mérito colectivo e intergeneracional, sobre el valor no natural generado y acumulado en esa sociedad por las generaciones pasadas.

Este supuesto es criticable y Risse es consciente de ello. Al discutirlo, él presenta y examina un argumento para fundar la demanda de que "the contemporary Dutch people have claims to all the value their predecessors added and that it is reasonable for this new generation to continue to block immigration even if they are enjoying a higher value of original resources per capita than everyone else" ${ }^{24}$. Evidentemente, la asunción fáctica del argumento es incorrecta: los holandeses no están subutilizando sus recursos naturales como el argumento sostiene. Sin embargo, para efectos de considerar el argumento supondré que ese es el caso y que Holanda, tal como Bolivia, está subutilizando y, por tanto, sus ciudadanos tienen una tasa de uso per cápita de recursos naturales originales mayor. El argumento afirma: (i) si el valor es generado solo en razón de una cultura en la cual participaron los predecesores, otros, que no son parte de esta cultura, no tienen demandas sobre el valor así generado; (ii) los holandeses están vinculados de un modo relevante a este proceso por ser los participantes actuales de esa cultura.

De acuerdo a su análisis, este argumento no justificaría la demanda de los holandeses contemporáneos a todo el valor generado por sus antepasados, ya que las acciones de los predecesores no pueden generar demandas que resuenan a través de los tiempos para el beneficio exclusivo de relativamente pocos. El caso sería similar al de las teorias de adquisición que se basan en la primera ocupación: los primeros pueden legítimamente demandar su territorio, pero esa ocupación no les da derecho a sus descendientes para excluir a otros. Sin embargo, según Risse, de esto no se sigue que, con tiempo, el valor agregado llegue a ser suficientemente parecido a recursos externos originales sobre los cuales toda la humanidad tiene demandas iguales. Ni los holandeses contemporáneos tendrían una demanda legítima a todo el valor generado, ni es plausible considerar todo ese valor en términos de propiedad común: "We are pointed to some intermediate view on whose details it is hard to be clear"55.

Su propuesta es la siguiente: si el valor de los recursos comunes es mejorado mediante tecnología o por otros medios, este valor debe ser considerado común solo en caso que esa tecnología o esos otros medios hayan llegado a estar fácilmente disponibles. Sin embargo, artefactos, ideas, prácticas, y otras

${ }^{54}$ Risse, M., On Global Justice, p. 157.

55 Ibid, p. 158. 
Inmigración, propiedad común de la tierra e igualitarismo de la suerte global

cosas para las cuales recursos externos han sido meramente posibilitadores, no deberían ser contados como comunes.

Es dificil dotar a esta idea de un sentido preciso. Risse afirma que los diques en Holanda (que generaron y generan valor económico) caen en la primera categoria, es decir, aumentan el valor de recursos comunes mediante tecnología fácilmente disponible y, por tanto, el valor así generado debe ser considerado como común ${ }^{56}$. No obstante, de acuerdo al principio que él mismo propone, esto solo puede valer desde el momento en que la tecnología para construirlos estuvo fácilmente disponible. Suponiendo que la disponibilidad no fue siempre el caso ${ }^{57}$, es decir, que la tecnología para construirlos se desarrolló en un momento particular y en un lugar determinado -por ejemplo, en la mente del inventor en Holanda-, entonces el valor que generan los diques no es común. En sentido estricto, el inventor de los diques ha desarrollado una idea, proceso en el cual los recursos externos fueron meramente posibilitadores, similar al escultor que utiliza la piedra para generar una figura representativa. Caen, en realidad, en la segunda categoría. Por tanto, en su debido momento (mientras la tecnología no ha estado fácilmente disponible), este valor debió ser considerado como exclusivo de los holandeses (asumiendo el carácter colectivo de la interpretación).

Si este es el caso, en cierto sentido la propuesta asemeja la idea de la validez temporal acotada de las patentes. Sin embargo, hay una diferencia relevante. En el caso de las patentes, la temporalidad está delimitado por normativas legales. A partir del momento temporal estipulado por la ley (10 años, 50 años, etcétera) el valor pasa a ser común. Antes de eso, es privado. Una convención de propiedad es lo que delimita la validez temporal del derecho de propiedad. Sin embargo, en el caso de los diques, la fácil disponibilidad de la tecnología está dada por las transferencias fácticas de información, como sostiene el principio diferenciador articulado por Risse. En sentido estricto, bastaria que esta transferencia no hubiese tenido lugar para establecer que el mérito permanece en su forma colectiva en el tiempo y que, de este modo, todo el valor generado por los diques sí pertenece a los holandeses. Esto no es trivial. Considérese el caso de las patentes farmacéuticas. Desarrollos farmacológicos generan valor

\footnotetext{
${ }^{56} \mathrm{Si}$ este fuese el caso, entonces gana plausibilidad su afirmación de que los holandeses disfrutan de un per cápita mayor de recursos comunes (subutilizan) y por tanto estarian sujetos a una demanda de conducta razonable para no impedir el ingreso de inmigrantes.

${ }^{57}$ La corrección fáctica de esta suposición es irrelevante. Lo importante es dar cuenta de un caso con las características expuestas. Si no aplica a los diques, puede aplicar a otro caso.
} 
(directamente, la ganancia de las farmacéuticas) y los que tienen una demanda legitima a este valor son las empresas farmacéuticas que los desarrollaron. Si la disponibilidad de la tecnología está mediada por condiciones fácticas, como en la ilustración mediante los diques, entonces bastaria que las fórmulas se mantuvieran suficientemente secretas para que este valor perteneciese siempre a las farmacéuticas.

A favor de Risse, sería posible argumentar que, si bien esta crítica se construye en base al ejemplo ilustrador de su teoría, se trataría de un mal ejemplo que termina por desdibujarla. De este modo, seria posible ensayar una segunda interpretación (que él mismo no ofrece) según la cual el que la tecnología esté fácilmente disponible no se debe entender como disponibilidad fáctica de la información relacionada, sino como disponibilidad legal. Es decir, en el caso de las patentes al que me referí, la validez temporal debe estar regulada por ley, como lo es en la actualidad, de modo que el valor se vuelve común a partir de un punto temporal determinado. Según este entendimiento, el derecho natural de propiedad estaría delimitado mediante convenciones legales de propiedad: la propiedad común original, que pasa a ser propiedad privada (mediante el valor generado por el trabajo), se transformaría nuevamente en propiedad común mediante una convención legal. Ahora bien, esta interpretación no carece de problemas. Por una parte, debe considerarse que la convención legal que se escoge en un momento temporal X, debe ser válida retroactivamente a todos los momentos que la preceden (para saber qué valor efectivamente los holandeses merecen hoy), lo que parece ser bastante arbitrario. O debe ofrecer diferentes limites convencionales en diferentes periodos de la historia, lo que, en ausencia de una justificación plausible de estos límites (justificación probablemente implausible sin referencia a las transferencias fácticas de información -lo que, a su vez, nos retrotrae al problema ya señalado-), parece un ejercicio arbitrario de casuística. Por otra parte, la teoría debiese explicitar plausiblemente los fundamentos normativos de la convención escogida. No es suficiente -al menos para una teoría filosófica de justicia global que, como esta, pretende ser una teoría ideal de justicia- afirmar que, dado que la diferencia entre la primera y la segunda categoría arriba señalada es en cierta medida arbitraria, "what count(s) as common may have to be left to a political process"58. Si esta fuese toda la historia, Risse podría haber obviado parte considerable de su libro ${ }^{59}$.

\footnotetext{
58 Risse, M., On Global Justice, p. 158.

59 Se puede contra argumentar afirmando que lo que la teoría de cumplimiento perfecto estipula es un principio general y que este principio puede ser interpretado de modos diferentes en el
} 
Ciertamente, hay buenas razones, desde diferentes perspectivas teóricas, para limitar la transferencia intergeneracional de propiedad. A modo de ejemplo, para el utilitarismo no parece haber razones para permitir el traspaso intergeneracional de bienes de modo no cualificado. Efectivamente, tanto Jeremy Bentham ${ }^{60}$ como John Stuart Mill establecen restricciones a este traspaso. Mill, por ejemplo, considera que la facultad de heredar no corresponde a un derecho natural (como sí lo sería desde la tradición lockeana), sino a uno sujeto dos restricciones legales: (i) una limitación de la suma que un individuo puede recibir como regalo o herencia a una cantidad suficiente para constituir una independencia moderada y (ii) un impuesto progresivo a toda herencia por sobre un cierto mínimo ${ }^{61}$. Tampoco Rawls ${ }^{62}$ considera que se trate de un derecho irrestricto, sino que este tipo de transferencia debe estar sujeta a las exigencias del Principio de la Diferencia, lo que posibilita impuestos progresivos a la herencia. Con su diferenciación entre circunstancias no escogidas -por las que no somos responsables- y decisiones -por las que sí lo somos-, Dworkin ${ }^{63}$ también condiciona la herencia a la compensación de aquellos en circunstancias dadas que los ponen en desventaja ${ }^{64}$. No obstante, a diferencia de la estrategia de Risse, en todos estos casos la respuesta que se intenta articular a la pregunta acerca de la justicia del traspaso intergeneracional de recursos se basa en principios y no en el proceso politico.

proceso legislativo. Este sería el caso, por ejemplo, de una teoría institucional como la rawlsiana, que establece cuatro niveles, la de los principios, la constitucional, la legislativa y la judicial. Así, la teoría de Risse establecería un principio general, esto es un principio de mérito (colectivo e intergeneracional) que el legislativo debe interpretar al establecer la convención de propiedad que lo limita y así definir lo común. Pero esto solo puede ser parcialmente correcto. Considere el muy discutido Principio de la Diferencia rawlsiano. Efectivamente, se trata de un principio de justicia que puede dar lugar a órdenes institucionales diferentes. Pero lo que está en cuestión es la interpretación del principio. Por su parte, lo que Risse pretende es que el proceso político resuelva la arbitrariedad que estaria a la base del principio: lo que el proceso politico debe definir es la prescripción legal del mérito y sus demandas asociadas. En sentido estricto, no se trata de interpretar un principio general (el del mérito), sino de constituirlo (o quizás de limitarlo en base a otros principios). Sin esta definición política, el precepto que lo precede es demasiado indeterminado para poder ser considerado como un principio que admitiría diversas interpretaciones.

${ }^{60}$ Bentham, J., "Principles of the Civil Code", en: Hildreth, R. (ed.), The Theory of Legislation, Londres: Trübner, 1882 (1840), p. 122.

${ }^{61}$ Mill, J.S., Principles of Political Economy: with Some of Their Applications to Social Philosophy, Robson, J.M. (ed.), Toronto: Toronto University Press, 1977 (1848), v. II, p. 811.

${ }^{62}$ Rawls, J., A Theory of Justice, pp. 277-278.

63 Dworkin, R., "What is Equality? Part 1: Equality of Welfare".

${ }^{64}$ Desde una perspectiva igualitaria, Brian Barry va incluso más allá y propone que, si bien la generación presente puede legitimamente derivar ciertas ventajas de los esfuerzos de la generación que la precedió, y quizás de la que precedió a esta última, la parte a legar al futuro que fue heredada de sus predecesores "should be regarded as by now forming part of the common heritage of mankind" (Barry, B., Democracy, Power and Justice: Essays in Political Theory, Oxford: Clarendon Press, 1989, p. 452). 


\section{4. ¿Propiedad común de la tierra o igualitarismo de la suerte global?}

El argumento de Risse refiere a las demandas de los Estados sobre su territorio y sus recursos. Se trata de demandas para controlar recursos escasos que, si bien no son derechos de propiedad, sí exigen ser consideradas desde la perspectiva de la justicia distributiva: ellas deben ser justificables para todos los seres humanos en tanto copropietarios de la tierra con un derecho a la satisfacción de necesidades básicas. La idea es atractiva, pero su alcance es limitado y su lógica cuestionable. La idea de ciudadanía global no es subsumible en la lógica de la copropiedad.

Como examinamos, la teoría tiene enormes dificultades para intentar delimitar lo que pertenece a la copropiedad (los recursos originales no hechos por el hombre y los hechos por el hombre que han pasado a ser comunes) y lo que no (los recursos hechos por el hombre que no han pasado a ser comunes). Sin embargo, no carece de razonabilidad sostener que la legitimidad de las demandas de los ciudadanos del mundo no depende del carácter original o generado por el hombre de los recursos, o del carácter común o privado de los bienes que las pueden satisfacer ${ }^{65}$.

Por una parte, para el igualitarismo de la suerte, que un bien o recurso sea resultado de la acción humana o sea original no puede ser un límite a la distribución requerida en razón de la justicia: la mitigación o compensación de los individuos por sus condiciones de vida desaventajadas no atribuibles a la agencia puede requerir medidas redistributivas sobre aquello que otros individuos han generado con sus acciones ${ }^{66}$. Por otra parte, dado que es dificil establecer con precisión la diferencia entre aquello atribuible a las decisiones y a las circunstancias, es razonable optar por el Principio de la Diferencia u otro similar, que asegure a los más desaventajados (por agencia o suerte) la mejor posición posible ${ }^{67}$.

\footnotetext{
65 Algunas razones para incluir tanto los recursos originales y los hechos por el hombre entre los activos comunes de la humanidad en Lenferma.

${ }^{66}$ En sentido estricto, el mérito tiene aquí un sentido institucional (y no natural), es decir, el mérito está mediado por la existencia de un aparataje institucional que se ajuste a las exigencias de la justicia redistributiva, de modo que aquellos bienes producidos por los individuos que son requeridos para cumplir con esta exigencia no pueden considerarse de su propiedad.

67 Por ejemplo, en su crítica a la teoría de Rawls, G.A. Cohen refiere a la dificultad teórica de la estructura rawlsiana para sostener la distinción entre, por una parte, la agencia en la determinación de nuestros fines y así la responsabilidad sobre los propios planes de vida, y, por otra parte, las virtudes productivas (esforzarse, etc.) que, como es conocido, Rawls retrotrae a la lotería. Sostiene, en su lugar, que la distinción entre suerte y agencia cruza ortogonalmente tanto la responsabilidad por los fines como la posesión de las virtudes productivas. Somos, por tanto, parcialmente responsables de nuestros planes de vida y de nuestras virtudes productivas (Cohen, G.A., "On the Currency of Egalitarian Justice”, en: Ethics, v. XCIX, 4 (1989), pp. 906-944
} 
Por cierto, y como examiné, la justicia social rawlsiana es relacional. Se basa en una cierta concepción de la sociedad como empresa cooperativa y de sus miembros como ciudadanos que se deben reciprocidad en la articulación de razones. Ciertamente, la distinción entre suerte y agencia juega un papel fundamental en ella, pero subordinado a lo que los ciudadanos en tanto ciudadanos se deben mutuamente. Ahora bien, hay otras estrategias disponibles. Es así posible articular una teoría no-relacional de la justicia distributiva que se base en una propiedad o argumentar que el tipo de relaciones que están a su base se encuentran también en la institucionalización de las relaciones internacionales. Evidentemente, Risse -como Rawls- rechaza la idea de que la institucionalización de las relaciones internacionales sea tal que se pueda hablar en ese contexto de justicia distributiva en un sentido similar al que se da en las sociedades politicamente organizadas. Como examiné, más allá de la satisfacción de necesidades básicas, la teoría solo ofrece una indeterminada demanda de conducta razonable. Pero hay razones atingentes para sostener -en un espíritu rawlsiano, que excede lo que él afirma- que hay razones no-relacionales para extender las demandas de justicia al contexto global: dado que, según Rawls, una condición suficiente para ser sujeto de justicia es la posesión de las dos capacidades morales (la capacidad de formar una concepción del bien y el sentido de justicia), habría razones para incluir dentro de los recipientes de las obligaciones de justicia a todos aquellos que las poseen, independientemente de su pertenencia nacional, de modo tal que la premisa igualitaria que subyace a su teoría, encuentre expresión global -y así, las desventajas asociadas con las circunstancias de nacimiento ${ }^{68}$ (esto es el país de nacimiento o, más exactamente, la ciudadanía adquirida según las reglas legales de su asignación) sean neutralizadas, compensadas o mitigadas desde la perspectiva de la justicia global-. Desde esta perspectiva, lo relevante es la riqueza de las sociedades, o las oportunidades a las que sus miembros pueden acceder, y no que se trate de recursos originales en vez de recursos retrotraibles (mediante una función de mérito) a la acción humana ${ }^{69}$.

(https://www.jstor.org/stable/2381239). Sin embargo, dado que establecer esta distinción, no ya entre clases identificables (planes de vida, virtudes productivas), sino a través de estas clases, es incluso más difícil, es razonable optar por un principio como el de la diferencia, que asegure la mejor posición posible a los peor situados. No es mi intención aquí defender este principio.

68 El concepto de "circunstancias de nacimiento" ha sido popularizado por Ayalet Shachar, quien propone un impuesto al Privilegio del derecho de nacimiento para compensarlas. En otro sitio se ha examinado críticamente esta teoría (Loewe, D., "Justicia global, impuesto a la ciudadanía y fronteras abiertas", en: Hybris. Revista de Filosofia, 9 (2018), pp. 243-273).

${ }^{69}$ De hecho, al considerar irrelevante la distinción entre recursos originales y hechos por el hombre, es posible evitar problemas técnicos serios en la operacionalización de la teoria: encon- 
Esta interpretación globalista no-relacional es próxima a un tipo de igualitarismo de la suerte global. En sus diferentes versiones, el igualitarismo de la suerte aspira a neutralizar los efectos de la suerte social y natural en la vida de los individuos. Esto se debe a que la perspectiva de la realización del propio plan de vida no debe depender de la lotería natural o social, ya que estas refieren a la suerte y no a la agencia (dondequiera que se trace la línea entre ellas). De modo similar, el hecho de nacer bajo la jurisdicción de un Estado particular no es menos resultado de la lotería que la posesión de un intelecto inferior al promedio o de condiciones sociales desaventajadas. En este sentido, Carens afirma: "Citizenship in Western liberal democracies is the modern equivalent of feudal privilege -an inherited status that greatly enhances one's life chances"70. Dado que nadie puede ser considerado responsable por haber nacido en una sociedad que comparativamente ofrece conjuntos reducidos de oportunidades, ya que se trata de contingencias moralmente arbitrarias o, con las palabras que Rawls utiliza en el caso de la justicia doméstica: "arbitrary from a moral point of view"71, no es razonable exigir a los individuos que carguen con los costes asociados con estas contingencias en el desarrollo de sus planes de vida. Así como los principios de justicia igualitarios deben neutralizar los efectos de la lotería social y natural, ellos deben también neutralizar o contrarrestar las consecuencias que se siguen de las circunstancias de nacimiento.

Tanto la justicia global distributiva ${ }^{72}$ como una política de fronteras abiertas $^{73}$ ofrecen modos, no excluyentes entre sí, para neutralizar o contrarrestar estas contingencias. En lo que respecta a las politicas de movilidad libre, resulta evidente que del igualitarismo de la suerte global no se sigue necesariamente una política de fronteras abiertas. Hay argumentos atingentes contra esta política como mecanismo para mejorar la distribución global de oportunidades o para mejorar la suerte de los más desaventajados. Por ejemplo, razones de eficiencia pueden llevar a oponerse a ella y optar en su lugar por principios

trar una medida singular (como precio mundial de mercado) de los recursos naturales no transados en el mercado y otorgar valor a recursos que requieren tecnología no disponible para ser explotados. Estos son -como Risse admite- problemas técnicos importantes y no es claro que puedan ser resueltos como él supone (el último mediante tasas de descuento).

70 Carens, J., "Aliens and Citizens. The Case of Open Borders", p. 252.

71 Rawls, J., A Theory of Justice, p. 63.

72 En otro sitio se ha sugerido un impuesto a las ventajas asociadas a la ciudadanía (Loewe, D., "Justicia global, impuesto a la ciudadania y fronteras abiertas").

${ }^{73}$ Una extensión de la teoría rawlsiana al caso de la inmigración, así como una crítica de su propia consideración teórico-normativa del fenómeno en Loewe ("Inmigración y el Derecho de Gentes de John Rawls"). Un examen critico del papel de las fronteras en Loewe ("Fronteras, Liberalismo e inmigración”, en: Pensamiento, v. LXXII, 272 (2016), pp. 633-654). 
de distribución global. Así, se argumenta que la capacidad de recepción de las naciones desarrolladas es superada por todos aquellos que se encuentran en circunstancias de miseria ${ }^{74}$; que dado que la emigración implica recursos variados (monetarios, educativos, emocionales, redes, etcétera), los que inmigran no suelen ser los que se encuentran en circunstancias más desaventajadas; que los procesos migratorios incrementan la fuga de cerebros, quitándole así a las naciones de origen recursos humanos necesarios para poder desarrollarse y, así, mejorar la situación de los más desaventajados. En este artículo no discutiré estos argumentos. Aunque ellos son relevantes, hay contraargumentos convincentes $^{75}$. De un modo fundamental para cualquier teoría que considere a los individuos como fuentes de razones normativas, y no como simples depositarios de utilidad social, resulta evidente que subordinar la posibilidad de los individuos para mejorar sus condiciones de vida cruzando fronteras a un supuesto bienestar o utilidad que se prevé alcanzar en un futuro indeterminado -en el cual los requerimientos normativos de la justicia global habrán sido realizados-, implica sacrificarlos en pos de la utilidad social. Aunque llegase a ser el caso, ya de por sí improbable, que algún conjunto de principios de justicia global fuese efectivo en el futuro, aquellos individuos a los que se negó la opción de mejorar sus condiciones de vida mediante la inmigración, dificilmente podrían disfrutar de aquellos, ya que probablemente se encontrarán muertos.

Desde la perspectiva teórica del igualitarismo de la suerte global, la libertad de los ciudadanos del mundo para cruzar fronteras no depende de su concepción de copropietario (con un derecho natural a la satisfacción de necesidades básicas), sino que se relaciona con la maximización de las oportunidades de los peor situados. Si bien este principio es objeto de controversia, no está sujeto a las críticas y a la indeterminación que caracterizan la apelación a la idea de la PCT para obtener respuestas normativas acerca de la inmigración.

Recibido: 04/09/2018

Aceptado: 08/03/2019

\footnotetext{
74 Pogge, T., "Migration and Poverty", en: Goodin, R. y P. Pettit (eds.), Contemporary Political Philosophy: An Anthology, Oxford: Blackwell, 2006, pp. 710-720; Pogge, T., "Migraciones y pobreza").

${ }^{75}$ Para una discusión de los principios globales de distribución versus principios de movilidad libre, $c f$. en Loewe, D., “Obligaciones de justicia: ¿Open Borders o justicia Distributiva?”.
} 


\section{Bibliografia}

Alvarez, D., "Propiedad común de la tierra, Derechos Humanos y Justicia Global", en: Isegoria, 43 (2010), pp. 387-405.

Arneson, R., "Against Relationalism in Global Justice", en: Ethics \& International Affairs, v. XXVIII, 4 (2014), pp. 477-487 (https://doi.org/10.1017/S0892679414000616).

Barry, B., The Liberal Theory of Justice, Oxford: Oxford University Press, 1972.

Barry, B., Democracy, Power and justice: Essays in Political Theory, Oxford: Clarendon Press, 1989.

Beitz, C., Political Theory and International Relations. With a New Afterword by the Author, Princeton: Princeton University Press, 1999 (1979).

Bentham, J., "Principles of the Civil Code", en: Hildreth, R. (ed.), The Theory of Legislation, Londres: Trübner, 1882 (1840).

Blake, M. y M. Risse, "Is there a Human Right to Free Movement? Immigration and Original Ownership of the Earth", en: KSG Working Paper No. RWP06-012 (2006) (https://ssrn.com/abstract=902383; http://dx.doi.org/10.2139/ssrn.902383).

Bull, M., "Help Yourself”, en: London Review of Books (2013) ( https://www.lrb.co.uk/ v35/n04/malcolm-bull/help-yourself).

Caney, S., "Cosmopolitan Justice, Responsibility, and Global Climate Change", en: Leiden Journal of International Law, 18 (1995), pp. $747-775$ (https://doi.org/ 10.1017/ S0922156505002992).

Caney, S., "Cosmopolitan Justice and Equalizing Opportunities", en: Metaphilosophy, 32 (2001), pp. 113-134 (https://doi.org/10.1111/1467-9973.00178).

Caney, S., "International Distributive Justice", en: Political Studies, v. XLIX, 5 (2001b), pp. 974-997 (https://doi.org/10.1111/1467-9248.00351).

Carens, J., "Aliens and Citizens. The Case of Open Borders", en: Review of Politics, v. XLIX, 2 (1987), pp. 251-273.

Carens, J., The Ethics of Immigration, Oxford: Oxford University Press, 2013.

Cavallero, E., "An Immigration-Pressure Model of Global Distributive Justice", en: Politics, Philosophy \& Economics, v. V, 1 (2006), pp. $97-127$ (https://doi. org/10.1177/1470594X06060621).

Cohen, G.A., "On the Currency of Egalitarian Justice", en: Ethics, v. XCIX, 4 (1989), pp. 906-944 (https://www.jstor.org/stable/2381239).

Dworkin, R., "What is Equality? Part 1: Equality of Welfare", en: Philosophy and Public Affairs, v. X, 3 (1981a), pp. 185-246 (https://www.jstor.org/stable/2264894).

Dworkin, R., "What is Equality? Part 2: Equality of Resources", en: Philosophy and Public Affairs, v. X, 4 (1981b), pp. 283-345(https://www.jstor.org/stable/2265047).

Fleischacker, S., A short History of Distributive Justice, Cambridge, Mass.: Harvard University Press, 2004.

Hont, I. y M. Ignatieff (eds.), Wealth and Virtue, Cambridge: Cambridge University Press, 1983.

Hohfeld, W., "Fundamental Legal Conceptions", en: Cook, W.W. (ed.), Fundamental Legal Conceptions as Applied in Judicial Reasoning, and Other Legal Essays, by Wesley Newcomb Hohfeld, New Haven: Yale University Press, 1919. 
Horn, C. Nichtideale Normativität, Fráncfort d. M.: Suhrkamp, 2014.

Kant, I., Die Metaphysik der Sitten, Akademie-Ausgabe VI (MS), pp. 205-493, 1797.

Kymlicka, W., Multicultural Citizenship. A Liberal theory of Minority Rights, Oxford: Clarendon Press, 1995.

Landes, D., The Wealth and Poverty of Nations, Nueva York: W. W. Norton, 1998.

Lenferna, A., "Common Ownership of the Earth: Towards a Theory of Global Justice for Refugees in a Warming World", en: Academia.edu (http://www.academia. edu/7036400/Refuge_in_a_Warming_World_Climate_Justice_Migration_and_ Common_Ownership_of_the_Earth).

Loewe, D., "Inmigración y el derecho de gentes de John Rawls. Argumentos a favor de un derecho a movimiento sin fronteras", en: Revista de Ciencia Politica, v. XXVII, 2 (2007), pp. 23-48.

Loewe, D., "Inclusión de animales no-humanos en un marco de argumentación teórico contractual”, en: Veritas, v. LIII, 1 (2008), pp. 145-162.

Loewe, D., "La justicia de la inmigración: algunos modelos argumentativos", en: Civitas, v. IX, 3 (2009), pp. 496-513.

Loewe, D., "Los náufragos de nuestro tiempo. El caso de los refugiados", en: Arbor, v. CLXXXVI, 744 (2010a), pp. 555-570 (https://doi.org/10.14422/pen.v72.i272. y2016.009).

Loewe, D., "Liberalismo, inmigración y justicia global: Obligaciones especiales hacia nuestros conciudadanos", en: Isegoría, 43 (2010b), pp. 435-458.

Loewe, D., "Obligaciones de justicia: ¿open borders o justicia Distributiva?" en: Arbor, v. CLXXXVIII, 755 (2012), pp. $475-488$ (https://doi.org/10.3989/ arbor.2012.755n3002).

Loewe, D., "Cuán liberal es la teoria de las relaciones internacionales de Rawls", en: Veritas, v. LX, 1 (2015a), pp. e1-e35 (http://dx.doi.org/ 10.15448/1984-6746.2015.1.17988).

Loewe, D., "Cinco dimensiones del cosmopolitismo", en: Civitas, v. XV, 4 (2015b), pp. e155-e173 (http://dx.doi.org/10.15448/1984-7289.2015.4.22311).

Loewe, D., "Fronteras, Liberalismo e inmigración”, en: Pensamiento, v. LXXII, 272 (2016), pp. 633-654 (https://doi.org/10.14422/pen.v72.i272.y2016.009).

Loewe, D., "Libertad y propiedad en la fundamentación del Estado kantiano", en: Ormeño, J. y M. Vatter (eds.), Forzados a ser libres. Kant y la teoría republicana del derecho, México D.F.: FCE, 2017.

Loewe, D., "Justicia global, impuesto a la ciudadanía y fronteras abiertas", en: Hybris. Revista de Filosofia, 9 (2018), pp. 243-273.

Milanovic, B., Global Inequality. A New Approach for the Age of Globalization, Cambridge Mass./Londres: Belknap Press, 2016.

Mill, J.S., Principles of Political Economy: with Some of Their Applications to Social Philosophy, Robson, J.M. (ed.), Toronto: Toronto University Press, 1977 (1848).

Miller, D., On Nationality, Oxford: Oxford University Press, 1995.

Miller, D., National Responsibility and Global Justice, Oxford: Oxford University Press, 2007.

Moellendorf, D., Cosmopolitan Justice, Oxford: Westview Press, 2002. 
Nussbaum, M., Frontiers of justice, Harvard: Harvard University Press, 2006.

Oberman, K., "Immigration, Global Poverty and the Right to Stay", en: Political Studies, v. LIX, 2 (2011), pp. 253-268 (https://doi.org/10.1111/j.1467-9248.2011.00889.x). Pogge, T., Realizing Rawls, Ithaca: Cornell University Press, 1989.

Pogge, T., World Poverty and Human Rights, Cambridge: Polity Press, 2002.

Pogge, T., "Migration and Poverty", en: Goodin, R. y P. Pettit (eds.), Contemporary Political Philosophy: an Anthology, Oxford: Blackwell, 2006, pp. 710-720.

Pogge, T., “¿Qué es la justicia global?”, en: Revista de Economía Institucional v. X, 19 (2008), pp. 99-114.

Pogge, T., “Migraciones y pobreza”, en: Arbor, 744 (2010), pp. 571-583 (https://doi. org/10.3989/arbor.2010.744n1218).

Rawls, J., A Theory of Justice, Cambridge, Mass.: Harvard University Press, 1971.

Rawls, J., Political Liberalism, Nueva York: Columbia University Press, 1993.

Rawls, J., The Law of Peoples, Cambridge, Mass.: Harvard University Press, 1999a.

Rawls, J., A Theory of Justice (revised edition), Cambridge, Mass.: Harvard University Press, 1999b.

Rawls, J., Justice as Fairness, A Restatement. Cambridge, Mass.: Belknap Press, 2001. Regan, T., The Case for Animal Rights, Londres: Routledge, 1984.

Risse, M., "On the Morality of Immigration", en: Ethics \& International Affairsv. XXII, 1 (2008), pp. 25-35 (https://doi.org/10.1111/j.1747-7093.2008.00127.x).

Risse, M., "The Right to Relocation: Disappearing Island Nations and Common Ownership of the Earth", en: Ethics \& International Affairs, v. XXIII, 3 (2009), pp. 281-300 (https://doi.org/10.1111/j.1747-7093.2009.00218.x).

Risse, M., On Global Justice, Princeton: Princeton University Press, 2012.

Risse, M., "Response to Arneson, de Bres, and Stilz", en: Ethics \& International Affairs, v. XXVIII, 4 (2014), pp. 511-522 (https://doi.org/10.1017/S0892679414000641).

Sandel, M., Liberalism and the Limits of Justice, Cambridge: Cambridge University Press, 1982.

Sandel, M., Justice: What's the Right Thing to Do?, Nueva York: Farrar, Strauß and Giroux, 2010.

Shachar, A., The Birthright Lottery. Citizenship and Global Inequality, Cambridge, Mass.: Harvard University Press, 2009.

Singer, P., One World: The Ethics of Globalization. New Haven: Yale University Press, 2004. Stilz, A., "On Collective Ownership of the Earth", en: Ethics \& International Affairs, v. XXVIII, 4 (2014), pp. 501-510 (https://doi.org/10.1017/S089267941400063X).

Tan, K., Justice, Institutions, and Luck, Oxford: Oxford University Press, 2012.

Velasco, J.C., El azar de las fronteras, México D.F.: FCE, 2016.

Walzer, M., Spheres of Justice, Nueva York: Basic Books, 1984. 